\title{
COMUNICAÇÃO, TURISMO E CONFIANÇA: PROCESSOS DE PARTICIPAÇÃO SOCIAL EM REGIÕES RURAIS
}

CARLISE SCHNEIDER RUDNICKI UNIVERSIDADE FEDERAL DO RIO GRANDE DO SUL PORTO ALEGRE, RIO GRANDE DO SUL, BRASIL E-MAIL: CARLISE.SCHNEIDER@UFRGS.BR

VERENICE ZANCHI

UNIVERSIDADE DE SANTA CRUZ DO SUL SANTA CRUZ DO SUL, RIO GRANDE DO SUL, BRASIL E-MAIL: VERENICE.ZANCHI@GMAIL.COM.BR

HTTP://DX.DOI.ORG/10.5902/2316882X22907 


\section{COMUNICAÇÃO, TURISMO E CONFIANÇA: PROCESSOS DE PARTI- CIPAÇÃO SOCIAL EM REGIÕES RURAIS}

Resumo: Este trabalho busca refletir sobre possibilidades e entraves nos processos de organização social de famílias que cultivam, ou já cultivaram, tabaco no Vale do Rio Pardo/ RS, a partir da implantação do turismo rural. Optou-se pela realização de grupos de discussão, entrevistas em profundidade e análise documental. Entende-se que, nestes espaços, assim como em outros, há uma crise de confiança nas instituições.

Palavras-chave: comunicação; turismo; confiança.

\section{COMUNICACIÓN, TURISMO Y CONFIANZA: PROCESOS DE PARTICI- PACIÓN SOCIAL EN REGIONES RURALES}

Resumen: Este trabajo busca reflexionar sobre las posibilidades y obstáculos en los procesos de organización social de las familias que cultivan o han cultivado, tabaco Vale do Rio Pardo/RS, a partir de la puesta en práctica del turismo rural. Hemos optado por la realización de grupos focales, entrevistas y análisis de documentos. Se entiende que, en estas zonas, así como otras, hay una crisis de confianza en las instituciones.

Palabras clave: comunicación; turismo; confianza.

COMMUNICATION, TOURISM AND TRUST: THE PROCESSES OF SOCIAL PARTICIPATION IN RURAL AREAS

This paper aims to reflect on possibilities and obstacles in social organization processes of family farming, or have cultivated, tobacco Vale do Rio Pardo / RS, from the implementation of rural tourism. We opted for the realization of focus groups, interviews and document analysis. It is understood that, in these areas, as in others, there is a crisis of confidence in the institutions.

Keywords: communication; tourism; confidence. 


\section{Como os sujeitos e as organizações têm ocupado, ou não, seus espaços}

Este artigo ${ }^{1}$ reflete sobre possibilidades e entraves nos processos de organização social de famílias que cultivam, ou já cultivaram, tabaco no Vale do Rio Pardo/RS, a partir da implantação do turismo rural. Este tem se apresentado como uma estratégia de resistência frente aos sistemas de governança das empresas e a possibilidade de alterar os modos de vida dos atores sociais. Para Kunrath (2010), paradoxalmente tem-se "[...] uma intensa mobilização de atores sociais e da significativa expansão de espaços institucionais abertos à participação destes atores" (2010, p. 3) e, por outro, ainda conforme o autor, as ciências sociais brasileiras apresentam uma diminuição das reflexões voltadas ao estudo dos processos de construção e atuação dos atores sociais desta sociedade. Como sujeitos da pesquisa tem-se famílias agricultoras que não mais produzem tabaco, ou desejam finalizar a produção, o cultivo do tabaco a partir do turismo rural, mais especificamente no "Roteiro Caminhos da Imigração", localizado no Vale do Rio Pardo/RS.

Os debates sobre comunicação e desenvolvimento iniciam nos anos 90, quando se ampliam os processos de globalização, degradação ambiental e aceleram os avanços tecnológicos emergentes. Dentre as novidades, sobressai-se a perspectiva da sustentabilidade como elemento norteador possível nas relações sociais no campo e nas ações de Assistência Técnica e Extensão Rural (ATER) e apoiada pelas políticas públicas agrárias. As ações de extensão governamentais têm atuado em torno da noção de sustentabilidade e na conversão da agricultura tradicional, introduzida pela modernização conservadora, por processos de produção agroecológicos. Entretanto, a agroecologia, entendida ainda como uma demanda urbana e de alto custo para a agricultura familiar, ainda tem sido incipiente, principalmente por se apresentar como algo fora da realidade das famílias rurais. Nesse sentido, este trabalho destaca a necessidade de ampliar esforços voltados ao tema, no sentido de entender como os sujei-

\footnotetext{
$1 \quad$ O artigo faz parte das discussões estabelecidas no projeto de pesquisa de pós-doutoramento intitulado "Comunicação, relações de poder e sistema do tabaco: discursos e estratégias de visibilidade e legitimidade empregados por Ongs, organizações públicas e indústrias do tabaco na mídia do Vale do Rio Pardo - RS". O estudo tem como fontes financiadoras CAPES e FAPERGS.
}

Rev.Cad.Comun. Santa Maria, v.20, n.3, art 1, p.15 de 31, set/dez.2016 
tos têm ocupado, ou não, seus espaços e pensado sobre novas possibilidades de modos de vida.

O Sistema de Produção do Tabaco ${ }^{2}$ foi criado na década de 1920, pela Souza Cruz Tabacos, e adotado na cadeia produtiva como um novo modelo de produção. Considera-se que o sistema tem sido bem sucedido no que refere ao número de produtores integrados, à inserção dos agricultores no mercado de trabalho e ao aumento da produção de tabaco. Esse Sistema é composto por um nexo de contratos formais e informais. Contratos são acordos de vontade entre pessoas a respeito de um negócio. Sem adentrar em questões jurídicas, pode-se acrescentar que, em regra, as pessoas devem ser capazes (maiores de idade, com consciência do que estão acordando) e que o objeto do negócio deve ser lícito. No âmbito dos contratos informais os processos de comunicação têm se desenvolvido basicamente a partir da relação estabelecida entre o orientador técnico e as famílias produtoras, ou seja, observa-se um ciclo fechado de relações e permeado pelas ações das empresas na comunidade, como ações de responsabilidade social e projetos educacionais em escolas municipais.

Tais reflexões são importantes para que se entenda os movimentos que compõem a caminhada das famílias que procuram alterar seus modos de vida e de produção, caso dos agricultores entrevistados nas proximidades dos roteiros turísticos localizados no município de Santa Cruz do Sul.

Destaca-se também que, independentemente das críticas às empresas e ao Sistema Integrado de Produção, a entrada das empresas na cadeia produtiva possibilitou a inserção desses agricultores no mercado e a garantia de compra do cultivo. Entretanto, as organizações tabagistas e agricultores familiares passam a enfrentar novos cenários institucionais quando, em 2003, foi criado um tratado internacional de saúde pública, denominado Convenção-Quadro de Controle do Tabaco . Após a ratificação do tratado internacional da Convenção-Quadro, em 2005, pelo governo brasileiro, vêm acontecendo negociações e sendo assinados protocolos que visam à criação e implantação de políticas que buscam diminuir a

2 Através deste sistema de produção as empresas fornecem para os agricultores familiares as sementes, agrotóxicos e insumos, bem como orientação técnica sobre o que e como plantar e também garantem a compra da safra.

3 O tratado surge das reivindicações da sociedade civil frente à gama de informações sobre os problemas que o cigarro pode causar à saúde humana. Ele foi ratificado por 57 países - dos 192 integrantes da Organização Mundial da Saúde (OMS).

Rev.Cad.Comun. Santa Maria, v.20, n.3, art 1, p.16 de 31, set/dez.2016 
plantação e oferecer alternativas para os agricultores. Tais negociações envolvem as empresas de tabaco, partidos políticos, movimentos sociais, governos municipal, estadual e federal, mídia e entidades representativas (do setor tabagista e dos agricultores).

Outra dimensão importante nestas análises se refere ao campo midiático. Há tempos os produtores de tabaco têm visibilidade nos meios de comunicação, tendo em vista as disputas entre as empresas e os órgãos de saúde pública nesta arena midiática. Os agricultores têm sido chamados a participar de entrevistas, seja em rádios, jornais ou em revistas corporativas das empresas. De um lado, a mídia local ressalta o senso comum de que eles praticam uma atividade altamente rentável e lucrativa e que, apesar de demandar uso intenso de mão-de-obra, pode ser realizada em pequenos lotes de terra. Ao mesmo tempo, os custos com mão de obra, agrotóxicos e investimentos em infraestrutura também são altos e não são contemplados nas discussões. Os produtores afirmam que a renda é o fator principal de permanência no cultivo do tabaco, apesar de confessarem que estão, permanentemente, endividados junto às empresas e aos bancos. De todo modo, o sistema de produção, conforme os entrevistados, gera uma "zona de conforto", ou ainda, insegurança em abandonar uma tradição familiar.

Neste cenário, as explicações sobre o comportamento das famílias produtoras (deixar ou não a produção do tabaco, dentre outras) têm sido a partir da lógica econômica, a qual incide diretamente sobre outras questões importantes, como a manutenção dos padrões da unidade familiar, questões de gênero, de juventude e processos de organização e mobilização social, por exemplo.

Nesse sentido, a atividade turística tem recebido destaque nos debates sobre as novas abordagens de desenvolvimento e se faz presente nos projetos de desenvolvimento regionais, estaduais e federais. Sob a luz do enfoque social, vê-se que a renda possibilita outras melhorias na vida, as quais podem gerar o resgate do sentimento de pertencimento destas famílias. O turismo promove, ainda, encontro e interação entre pessoas de diferentes culturas e hábitos. No entanto, outras questões inerentes e conflituosas fazem parte deste cenário, principalmente no que tange à hierarquia familiar. Os jovens e as mulheres, antes invisíveis na relação patriarcal estabelecida no trabalho familiar da produção do tabaco, passam a dividir as cenas com aquele que, antes, era responsável pelas decisões. 
A ATURVARP (Associação de Turismo do Vale do Rio Pardo) organiza uma reunião mensal na região, em diferentes municípios. Quem comparece às reuniões é, em regra, o homem da casa (marido/pai), mesmo que as mulheres e filhos participem ativamente da divisão de tarefas e estejam à frente do atendimento ao público e do gerenciamento, é ele quem representa a propriedade. Perguntou-se porque outros membros não participavam e a resposta foi unânime: "ele gosta de estar lá, conversar com os amigos, colocar a conversa em dia", confessa, sorrindo, a esposa de um proprietário.

Em um contexto de valorização do meio rural, das potencialidades do lugar a partir do território, visando o desenvolvimento da região, surge o turismo, para o agricultor familiar, como uma atividade econômica complementar e conflituosa.

As relações instauradas e vividas pelos sujeitos em estudo encontram-se fundadas em contratos formais baseados em relações de proximidade, ou seja, mediados/conduzidos pelos técnicos agrícolas. Estes sujeitos, contratados pelas empresas de tabaco, são, em geral, oriundos das regiões/comunidades em que atuam. Por esse motivo, as relações informais podem ser pensados a partir das relações de confiança, como importantes instrumentos de governança para as empresas. Conforme Nooteboom, Woolthuis e Hillebrand, "relações que implicam investimentos específicos criam dependência e vulnerabilidade que favorecem comportamentos oportunistas" (NOOTEBOOM; WOOLTHUIS; HILLEBRAND, 2005, p.813). Tal citação ressalta que os espaços de manobras se encontram influenciados por outras questões, dentre elas a dependência e a vulnerabilidade dos sujeitos perante um sistema vigente.

Essa "confiança" no sistema de produção, que propiciaria certa "acomodação", inclusive no momento de se organizar e buscar informação, certamente interfere nos processos de mobilização e de organização social. Ao justificarem sua permanência no sistema de produção do tabaco e confirmarem o descrédito em ações associativas, utilizam argumentos econômicos. Segundo eles, trabalhar sozinho é mais fácil e mais rentável, pois não confiam nos parceiros: nunca "deu certo" uma cooperativa na região, confidencia um entrevistado. Há um visível descontentamento em relação aos movimentos sindicais do setor (Movimento dos Pequenos Agricultores - MPA), sindicatos e associações na região. Contrariando as enunciações pautadas em aspectos econômicos, as falas também exprimem o desejo da mudança, a falta de liberdade para negociar com

Rev.Cad.Comun. Santa Maria, v.20, n.3, art 1, p.18 de 31, set/dez.2016 
as empresas e a individualidade do "outro" como um problema para o desenvolvimento do roteiro.

No ponto de vista de Ostrom (2008), existe outra forma de explicar o comportamento humano, que não a partir da maximização de ganhos. Dessa perspectiva, os sujeitos podem ser múltiplos, ou seja, em alguns momentos pessoas guiadas por lógicas egoístas racionais que cooperariam mediante a possibilidade de reciprocidade (desde que recebam algo em troca mediante a cooperação do outro).

Conforme destaca Peruzzo (2005), a participação envolve a tomada de decisões políticas e metodologias adequadas. Ademais, prossegue a autora, a estratégia de comunicação focada apenas na prática das organizações tradicionais de ação comunitária e da grande mídia propicia pensar “o meio de comunicação apenas como fim (conscientizar, convencer, educar) e não como meio facilitador de um processo de auto emancipação cidadã" (PERUZZO, 2005, p.38). Assim, mobilizar-se é um processo complexo e que envolve variáveis distintas e em âmbitos diversos. Nesse sentido, acredita-se na relevância de conectar o contexto socioeconômico e a capacidade e a vontade de mobilização (dos agricultores) às discussões destacadas pela mídia local.

\section{Análise das falas e contribuições teóricas}

Este estudo de caráter teórico-empírico vem sendo realizado no Vale do Rio Pardo/RS. A coleta dos dados primários aconteceu de 2012 a 2015. Em primeiro lugar foi efetuada uma revisão de literatura sobre o tema de estudo - sistema produtivo do tabaco -, questões contextuais, sistema político-econômico. Em segundo, foram realizadas pesquisas online no jornal “A Gazeta do Sul”. A Gazeta faz parte de um grupo local (rádio e jornal), concorrente do Grupo RBS TV Santa Cruz do Sul (filada da Rede Globo). Também foram feitas leituras sobre temas fundamentais para os objetivos de estudo, tais como: comunicação, comunicação comunitária e turismo rural. Para aprofundamento da pesquisa, e no intuito de compreender o fenômeno em estudo, foram empregados os seguintes procedimentos metodológicos para a investigação empírica: entrevistas individuais em profundidade e a realização de grupos de discussões como unidades de análise. A opção por essa região deve-se ao fato de ser a mais representativa na produção do tabaco no Brasil. Em primeiro lugar foi fei-

Rev.Cad.Comun. Santa Maria, v.20, n.3, art 1, p.19 de 31, set/dez.2016 
ta uma pesquisa bibliográfica e documental, a partir de dados secundários, reportagens na mídia local e publicações científicas. Em um segundo momento, foram realizadas entrevistas em profundidade e organizados grupos de discussão com a população rural. Destaca-se que as autoras trabalham com pesquisa na região desde 2006, o que propiciou uma facilidade para realizar as entrevistas. 0 critério de escolha dos grupos de discussão foi: a) sujeitos produtores de tabaco do Vale do Rio pardo/RS e b) indivíduos com certo grau de proximidade (parentesco ou amizade). Para definir-se a quantidade de grupos e indivíduos considerou-se o critério da saturação, quando as respostas começavam a repetir-se, sem acréscimo de novas informações. As discussões aconteceram conforme o método de William Gamson (2011), sendo estas realizadas nas casas dos sujeitos ou, ainda, em espaços naturais e entre pessoas que se conhecem.

Foram analisadas (neste trabalho, pois o artigo é parte dos dados de pós-doutoramento da autora) três entrevistas realizadas com agricultores que fazem parte do roteiro "Caminhos da Imigração" ${ }_{4}^{4}$ e três grupos de discussão. Localizado no distrito de Boa Vista, encontra-se à $15 \mathrm{~km}$ do centro da cidade de Santa Cruz do Sul. O roteiro teve alterado seu nome algumas vezes: "Caminhos Verdes de Boa Vista”, "Roteiro Rural”, "Colonial de Boa Vista", "Roteiro de Boa Vista", "Roteiro Turístico Caminhos de Boa Vista" e "Roteiro Caminhos de Boa Vista". Em 2002, dois anos após seu primeiro lançamento, foi reconfigurado a partir de um estudo realizado pela UNISC (Universidade de Santa Cruz do Sul) em parceria com a Prefeitura Municipal de Santa Cruz do Sul. Os sujeitos não participam de uma associação representativa.

Dentre os paradoxos encontrados nestes espaços, tem-se, como um dos atrativos do roteiro uma antiga cooperativa, criada, inicialmente para a compra do fumo e desativada desde a década de 70. Na Cooperativa Agrícola Linha Santa Cruz, nos anos 50, foi construído um salão, local em que eram realizados bailes e festas da comunidade. A mesma é lembrada por eles como 'algo que não deu certo', porque 'cooperativa e associação nunca dá certo', relata um dos sujeitos durante os debates em grupo. 0 local resume-se a 'uma vista bonita'. Sobre as festas comunitárias, não há mais tempo para organizá-las ou participar destas.

4 Dentre as principais atividades nas propriedades tem-se: "colhe e pague" (verduras, frutas), venda de carne, organização de almoços, aluguel de casas/ alojamentos e espaço para festas.

Rev.Cad.Comun. Santa Maria, v.20, n.3, art 1, p.20 de 31, set/dez.2016 
Os indivíduos relataram inúmeros problemas de relacionamento com a prefeitura e com a Secretaria de Turismo. Um entrevistado, por exemplo, descreveu que, em 2012, durante a maior feira da região (EXPOAGRO), a Associação de Turismo do Vale do Rio Pardo (ATURVARP) não distribuiu material de divulgação do roteiro. Segundo eles, apenas algumas rotas/roteiros recebem apoio do governo local. Prosseguem denunciando que algumas propriedades foram inseridas em virtude de "jogos políticos", pois algumas propriedades não teriam 'nada a ver' com turismo rural. A gestão deste roteiro é efetivada pela prefeitura, visto que não há uma associação. A dificuldade de exercer práticas coletivas foi o maior entrave declarado pelos integrantes, ou seja, a falta de interesse de participar de ações e resolver problemas coletivos. Ao mesmo tempo, se sentem subtraídos das decisões. A escassez de tempo, segundo eles, não permite 'pensar na vida' e se organizar.

Todos reivindicaram informação com qualidade e evidenciaram como problema maior o descaso da comunidade em participar das reuniões gerenciadas pela Secretaria de Turismo. Também destacaram a necessidade da construção de uma associação de turismo pelo grupo.

Além da ausência de organização, os sujeitos acreditam que há poucos atrativos e deficiências em termos de agências receptivas, sinalização e infraestrutura (estradas e acesso às propriedades). Também há problemas quanto ao acesso à internet na região. Apesar do acesso à internet ter sido ampliado, o custo é alto e a qualidade dos serviços é baixa. Observou-se que a capacidade de uso das ferramentas, principalmente no que tange à busca de informações e de divulgação de seus produtos turísticos, também merece atenção. Aqueles que já acessam a rede mundial a utilizam não para busca de informações, mas, geralmente, apenas para lazer, "passar o tempo" em redes sociais digitais, como o facebook.

As famílias confessam estar em contato com a Secretaria de Turismo, mas de forma aleatória e individual. Também afirmam ter participado de um curso do Serviço Nacional de Aprendizagem Rural (SENAR/RS) voltado ao planejamento da atividade turística. Segundo os entrevistados, a melhor forma de obter informações sobre o ramo, e pensar sobre o gerenciamento, tem sido viagens/passeios em regiões como a serra gaúcha, por exemplo. Retoma-se, aqui, a partir de Peruzzo, a necessidade de compreender que há uma "[...] exclusão do acesso à comunicação no sentido da capacidade de abstração e de expressão de pessoas" (PERUZZO, 2005,

Rev.Cad.Comun. Santa Maria, v.20, n.3, art 1, p.21 de 31, set/dez.2016 
p. 39-40). Assessoria, ou mesmo de assistência técnica, são elementos cruciais nos processos de mudança e de inovação no campo, acredita-se na relevância da organização e da mobilização social, como um processo comunicativo (MAFRA, 2006). A área de relações públicas, em perspectiva estratégica, inspira a dimensão estratégica e instaura o debate, no sentido de qualificar as relações e a mobilização social (MAFRA, HENRIQUES e BRAGA, 2004). Conforme uma agricultora, o tabaco ainda é desenvolvimento para a região:

[...] mas - o desenvolvimento - é uma coisa que tem que vir com uma formação de acompanhamento técnico, não só o técnico chegar na tua propriedade. Tá o técnico chegou. Faz a visita do cadastro rural, tudo bem. Faz a visita e pergunta, como é que tá o que que tem? Bom, assina aqui, estou indo embora, tchau. Isso não é acompanhamento técnico. (AGRICULTORA 1, 2015).

Ao serem questionados sobre a participação em projetos governamentais voltados à diversificação produtiva na região, as respostas demonstraram descrédito nos governos e organizações do meio rural. A maior parte dos entrevistados disse não saber de projetos do governo federal. Destaca-se que, em 2012, o Ministério do Desenvolvimento Agrário selecionou entidades na região de tabaco, no intuito de fornecer ajuda técnica aos agricultores com interesse em diversificar a propriedade. Denominado Projeto de Assistência Técnica e Extensão Rural (ATER), as ações, não divulgadas na mídia local, foram realizadas em parceria com a Cooperativa Mista dos Fumicultores do Brasil e atenderam 1.600 famílias na região.

É pertinente apontar a "confiança" como um tema a ser contemplado em estudos posteriores, pois esta, seja entre os pares (comunidade), seja frente às entidades que constituem o cotidiano dos sujeitos (famílias, empresas, igrejas, associações, governos), permeia as relações e permite solidariedade. Elinor Ostrom tem focado na confiança que se opõe à perspectiva encontrada na "Tragédia dos Comuns", artigo do biólogo norte-americano Hardin, publicado em 1968. Ele argumenta que a competição, e não a colaboração, frente a um produto natural escasso, oferece um final em que as escolhas se baseiam nas necessidades individuais. Preocupado com o crescimento da população humana, a solução viria de um controle severo e de incentivos via punições. A descoberta no trabalho de campo de sua pesquisa foi que os sujeitos buscam conversar e conquistar a

Rev.Cad.Comun. Santa Maria, v.20, n.3, art 1, p.22 de 31, set/dez.2016 
confiança um dos outros, de uma forma recíproca. Ao perguntar-lhes se estivessem famintos e com pouca comida e outra pessoa precisasse dela "Você daria metade a ela? Em muitas regiões, sim. Mas é uma decisão difícil se não houver confiança e trabalho em conjunto" (CANAL FUTURA, 2010). Percebe-se que é possível pensar em outras formas de comportamento humano, sendo este o grande desafio, ou seja, a partir do referencial teórico Institutional Analysis and Development (IAD), Ostrom analisa como as instituições são formadas, como elas operam, seu dinamismo e como influenciam o comportamento da sociedade. Se o comportamento dos indivíduos perante os dilemas sociais, segundo Ostrom e Walker (2005), pode ser mais bem compreendido quando a racionalidade limitada dos indivíduos passa a ser vista a partir da reciprocidade, baseada em relações anteriores, pretende-se mostrar contribuições teóricas que se opõem ao comportamento estreitamente conectado ao auto interesse. A autora (2008) ao referir-se às relações entre os indivíduos e as instituições, estabelece como base a confiança, ao observar a "arena" em que as interações ocorrem, recupera as regras empregadas pelos participantes que ordenam os relacionamentos, os atributos que estruturam e que são estruturados nessas interações e os atributos das comunidades na qual a arena particular está colocada. Em termos gerais, as instituições são as receitas que os humanos usam para organizar todas as formas de interação repetitivas e estruturadas, incluindo as famílias, bairros, mercados, empresas, ligas esportivas, igrejas, associações privadas e os governos em todas as escalas. Indivíduos que interagem em situações estruturadas enfrentam escolhas sobre as ações e estratégias que irão aderir, tendo em vista as consequências para si e para os outros. Conforme se verifica nos argumentos de Ostrom, Gardner e Walker (1994), a análise institucional refere-se ao entendimento de diversas variáveis, ou seja, regras, padrões de interação, atributos da comunidade em estudo, condições materiais, dentre outros. Portanto, ao analisar a relação entre instituições e atores sociais, ressaltam a falta de confiança, de comunicação, de informação e da construção de um plano comum.

Conforme Baldissera (2009), algumas atividades turísticas se desenvolvem a partir de "tentativa e erro", já que não apresentam um planejamento estratégico, nem definem claramente os atrativos/produtos ou definem seus públicos. Da mesma forma, carecem de pesquisas capazes de diagnosticar e mensurar os resultados das ações de comunicação. Apesar

Rev.Cad.Comun. Santa Maria, v.20, n.3, art 1, p.23 de 31, set/dez.2016 
do conhecimento em gestão ainda ser incipiente, os sujeitos se informam e criticam a atuação das organizações do tabaco, mostrando conhecimento e informação sobre o setor: "[...] só nos três meses que eles exportaram de duzentos e trinta e poucos foi para duzentos e oitenta e sete milhões de dólares". (AGRICULTOR 2, 2015).

Neste estudo, evidencia-se a falta de confiança no ambiente, nas comunidades e no governo. A prefeitura e a Secretaria de Turismo do município, conforme relatado, pouco colaboram com a divulgação do roteiro, a começar pela falta de sinalização. Participantes do roteiro analisado enfatizam que estão em desvantagem na região, pois não estão organizados em associação. Segundo os sujeitos, moradores de outra comunidade, Rio Pardinho, por exemplo, pelo fato de estarem organizados em associação apresentam vantagens, principalmente, quanto a capacidade ações coletivas que incidem diretamente na ampliação da infraestrutura, como rede de telefonia, asfalto e iluminação. Os entrevistados, ao serem questionados sobre o motivo de não se organizarem em associação, declararam que as pessoas da rota são individualistas, incapazes de discutir e pedir ajuda, em grupo, ao poder público local. Da mesma forma, quando o pesquisador insiste e pergunta porque eles não tomam a iniciativa, dizem que é um trabalho familiar, demanda alta dedicação e que não há tempo para tratar de questões "fora da propriedade". Ao mesmo tempo, nas falas, atentou-se que as famílias realizam visitas individuais à prefeitura, ora para solicitar melhoramentos na infraestrutura da propriedade, do roteiro ou pedir ajuda na divulgação.

Conforme os resultados da pesquisa, é preciso compreender a organização e dinâmica do espaço agrário/rural, no intuito de diferenciar os territórios e ajudar no entendimento e conhecimento de políticas públicas que viabilizem novas atividades econômicas. O incentivo da multifuncionalidade na agricultura familiar e a ampliação da participação popular são estratégias que podem fortalecer o capital social das regiões e promover debates sobre cidadania.

Entende-se que, nestes espaços, assim como em outros, há uma crise de confiança nas instituições. Tal questão, também é contemplada no pensamento de Ostrom, a qual considera a confiança um importante fator para os indivíduos manterem suas reputações como membros confiáveis da comunidade (OSTROM; WALKER, 2005). Tal observação evoca a importância da imagem (percepção) que as pessoas têm no ambiente em que

Rev.Cad.Comun. Santa Maria, v.20, n.3, art 1, p.24 de 31, set/dez.2016 
interagem com as demais. A situação difere-se quando os sujeitos se relacionam não com desconhecidos, mas com pessoas com quem se tenha desenvolvido uma relação de confiança. A autora considera que as "[...] normas de reciprocidade e confiança são necessárias para a sustentação de longo prazo de regimes de auto governança" (OSTROM; WALKER, 2005, p. 287). Nesse sentido, pode-se refletir sobre as condições de governança perante um processo constante de adaptação que apresenta uma expressiva vigência ao longo do tempo. Por isso, um elemento indispensável refere-se à confiança que se estabelece entre as redes de relações sociais, seja em um nível mais imediato (confiança interpessoal), seja baseada em encontros anteriores, ao longo do tempo, as quais incentivam os sujeitos a permanecerem confiando. Entretanto, para os entrevistados os modelos associativos e cooperativos pressupõem um ideário socioeconômico e representam um grupo de indivíduos que juntos buscam promover meIhores condições de venda de seus produtos. A racionalidade, nesses grupos estudados, indica a associação como um espaço que não se solidifica na solidariedade, mas na maximização dos lucros. A antiga cooperativa da linha Santa Cruz, patrimônio histórico do roteiro, ilustra a falta de tempo destinado a ações e negociações coletivas. Assim se tem a evocação da cultura e das informações disponíveis (ou da qualidade da informação) como fatores relevantes para entender as relações que se estabelecem entre sujeitos e instituições. Assim, resgatando as ideias de Ostrom, os fatores relevantes para o sucesso ou fracasso de um acordo de cooperação referem-se à construção de um plano em comum, ao tipo das lideranças, ao entendimento das consequências das ações dos envolvidos, enfim, se as informações e o conhecimento forem suficientes, já que "Há um número de fatores relacionados ao grupo, à liderança, ao desenvolvimento, à confiança que têm entre eles" (CANAL FUTURA, 2010).

Acredita-se que o debate importa, e muito, para a discussão sobre políticas públicas federais na região. A partir da assinatura do tratado internacional de saúde pública, constitui-se um confronto político e econômico, em busca da legitimidade das diferentes vozes e verdades (saúde versus iniciativa privada). O governo local tem se posicionado a favor das empresas de tabaco não havendo, assim, um diálogo com o governo federal, no que diz respeito à diversificação das propriedades.

Para as mulheres que trabalham no roteiro, o turismo significa a possibilidade de lidar com o público, servir, oferecer, receber pessoas "diferen-

Rev.Cad.Comun. Santa Maria, v.20, n.3, art 1, p.25 de 31, set/dez.2016 
tes" em suas casas e conhecer outras realidades. Ao mesmo tempo, reconhecem que a distribuição das tarefas é "meio complicada", pois não há uma divisão de tarefas, todos fazem tudo, herança de padrões de trabalho da agricultura familiar. Aqueles que já abandonaram produção destruíram a estrutura (galpões e fornos) para não voltar a plantar: "sou capaz de não depender do fumo, fazer algo diferente para não depender mais", desabafa a entrevistada. E retoma: "O bem-estar mudou, quando não se tem turismo e só plantar, colher, estar de sol a sol no mesmo lugar, sem contato com as pessoas, sem conhecimento da vida de outras pessoas, antes era apenas de casa para a lavoura, da lavoura para a casa", finaliza.

Ainda, a ideia de comunicação organizacional é desconhecida para as instituições e, mesmo, para as ciências da terra. Para Gonçalves e Fellipi, os conceitos de cidadania e participação, responsabilidade social e ambiental, tão caros a nossa área, perpassam o tema do desenvolvimento e sustentabilidade (GONÇALVES e FELLIPI, 2014).

Seguindo essa linha, importa ultrapassar o caráter instrumental no sentido de discutir a comunicação nas organizações como um espaço capaz de ensejar processos comunicacionais que estimulem os atores e instituições sociais numa perspectiva participativa e plural. Consequentemente, urge refletir sobre o papel das relações públicas na articulação e para o desenvolvimento nas instituições no meio rural, a partir da reflexão sobre a interação social e a alteridade nas práticas profissionais, pensando, assim, a compreensão dos sujeitos nos processos, não apenas dos meios.

Importa também destacar que a proposta de entendimento das lógicas de reprodução da família, não centradas apenas no chefe de família, remete o pesquisador e à universidade a uma compreensão mais ampla, pois para este grupo a reprodução familiar, a orientação, e não a sobrevivência econômica, aparece como elemento mais relevante (WANDERLEY, 2001; TEDESCO, 2001; CAPORAL e COSTABEBER, 2007).

\section{Reflexões finais}

A possibilidade de exercício da crítica, das mudanças e da participação dos atores sociais, por exemplo, traz um terreno fértil para reflexões acerca das relações dos sujeitos com os meios de comunicação. Ao analisar e discutir este cenário empírico se percebe que o caminho de pesquisa é vasto, desafiante e urgente, diante das demandas da sociedade aos profis-

Rev.Cad.Comun. Santa Maria, v.20, n.3, art 1, p.26 de 31, set/dez.2016 
sionais de mercado e educadores. Isto posto, abordar o desenvolvimento das relações no campo é fundamental para compreender a complexidade das mudanças no ambiente socioeconômico que impactam não apenas a vida no rural, mas toda a sua dinâmica em relação aos espaços urbanos. As transformações sociotécnicas (ou seja, diferentes apropriações das tecnologias pelos atores sociais) decorrentes dos avanços científicos e tecnológicos, associados à necessidade cada vez maior de "novidades", têm demonstrado suas limitações e as múltiplas facetas que emanam de realidades distintas, por vezes, conflitantes. Os processos de desenvolvimento são de continuidade e mudanças, que reproduzem e reafirmam as características agrícolas, como as práticas e usos das tecnologias, as quais são transformadas no decorrer do tempo.

O cotidiano do agricultor encontra-se permeado não apenas pela incerteza (que pode ser visualizada no caso das intempéries do clima e no interesse das pessoas em visitar os locais), e pelo risco, dado que esse, diferente daquela, não pode ser previsto, encontrando-se em cenários complexos. Mas pela falta do tempo. Tempo para organizar festas comunitárias, conversar com os vizinhos e trocar experiências, participar das reuniões e organizar uma associação. A falta de organização verificada no gerenciamento dos empreendimentos, tanto no que concerne à falta de controle financeiro (custos de produção, dívidas com bancos e empresas) soma-se à baixa confiança em cooperativas e associações.

Considera-se que a informação desempenha um relevante papel para entender as relações de confiança e a falta desta na comunidade. Tendo em vista a importância dos discursos econômicos na região, na economia, a confiança é ressaltada a partir da limitação encontrada na assimetria de informações entre os atores. A confiança estudada em algumas correntes teóricas econômicas ressalta a frequência de transações como fonte desta. Neste estudo, ressaltam-se outras possibilidades de pensar o assunto. A assimetria de informações se refere, aqui, não a um pressuposto, conforme preconiza grande parte do pensamento econômico. Minimizar esta assimetria demanda uma alteração nos modos de vida do grupo, exige debates e a composição de planos comuns. Os sujeitos localizaram a individualidade como entrave para a organização dos mesmos. E confessaram a relevância do turismo e a oportunidade e o desejo do encontro com o outro, de conviver com a alteridade.

Parece evidente a necessidade de pesquisas que atendam essa carên-

Rev.Cad.Comun. Santa Maria, v.20, n.3, art 1, p.27 de 31, set/dez.2016 
cia investigativa de modo a ampliar e complexificar a compreensão sobre essa realidade e, como desdobramento, estimulem outros estudos e avancem na construção do conhecimento no sentido de subsidiar a sociedade civil para que melhor compreenda sua realidade e decida pelas ações mais adequadas.

A pesquisa também atenta - no sentido de desvelar e compreender para as relações de poder que se materializam entre o setor público, a comunidade e a iniciativa privada, bem como para os possíveis efeitos que se exercem sobre a comunidade (população local). Importa observar que a compreensão dessas relações estratégicas e de poder, bem como suas conexões e inscrições nas relações socioculturais, é relevante caso se deseje uma intervenção orientada por princípios verdadeiramente democráticos. A socialização desse tipo de informação poderá permitir que se questionem tais fazeres para que, no "jogo" de relações não prevaleçam apenas os interesses de "alguns" em detrimento dos da maioria. Ganha-se, em algum grau, efetividade na crítica ao sistema. E mais, permite identificar a necessidade que determinados grupos apresentam. 


\section{REFERÊNCIAS}

BAKER, G.; GIBBONS, R.; MURPHY, K. J. Relational contracts and the theory of the firm. The Quarterly Journal of Economics, Cambridge, v. 117, p. 39-84, Feb. 2002.

BALDISSERA, R. A comunicação (re)tecendo a cultura da sustentabilidade em sociedades complexas. In: KUNSCH, M. M. K. (Org.) Comunicação Organizacional: linguagem, gestão e perspectivas. V. 1. São Paulo: Saraiva, 2009. p. 135-164.

CANAL FUTURA. Canal Futura entrevista Elinor Ostrom, prêmio Nobel de Economia. 25 de março de 2010. Disponível em < http://www.canal-futura.org.br/main.asp?ViewID=\%7BD2EF690E\%2D49AB\%2D498F\% 2D9 011\%2D7957E4D9F702\%7D\&params=itemID=\%7B6BE4CF9E\%2D DE64\%2D482E\%2DA 8F3\%2D6BDB7B7588FA\%7D; \&UIPartUID=\%7BD9 0F22DB\%2D05D4\%2D4644\%2DA8F 2\%2DFAD4803C8898\%7D> Acesso em: 23 maio 2014.

CAPORAL, F. R; COSTABEBER, J.A. Por uma nova extensão rural: fugindo da obsolescência. In: CAPORAL, F. R; COSTABEBER, J.A. Agroecologia e extensão rural: contribuições para p desenvolvimento sustentável. Brasília: MDA/SAF/DATER, 2007.p.5-15.

GAMSON, W. Falando de política. Belo Horizonte: Autêntica, 2011.

GONÇALVES, G.; FELIPPI, A. Comunicação, Desenvolvimento e Sustentabilidade. Santa Cruz do Sul, UNISC. Coleção Relações Públicas e Comunicação Organizacional, v. 2. 2014. p. 3-7.

HARDIN, G. The Tragedy of the Commons. 1968. Science, New York, v. 162, n. 3859, p. 12431248, Dec. 1968.

KUNRATH, S.M. De volta aos movimentos sociais? Reflexões a partir da literatura brasileira recente1. Ciências Sociais Unisinos, São Leopoldo, n. 46, v. 1, jan./abril, 2010. p. 2-9.

MAFRA, R.; HENRIQUES, M.; BRAGA, C. O Planejamento da Comunicação para a Mobilização Social: em busca da co-responsabilidade. In: HENRIQUES, Márcio (org). Comunicação e Estratégias de Mobilização Social. Belo Horizonte: Autêntica Editora, 2004. p. 33-58.

MAFRA, R.; HENRIQUES, M.; BRAGA, C. O Planejamento da Comunicação para a Mobilização Social: em busca da co-responsabilidade. In: HENRIQUES, Márcio (org). Comunicação e Estratégias de Mobilização Social. Belo Horizonte: Autêntica Editora, 2004. P. 33-58.

NOOTEBOOM, B.; WOOLTHUIS; R. K.; HILLEBRAND, B. Trust, Contract and Relationship Development. Organization Studies, Thousand Oaks, n. 26, p. 813-840, June. 2005.

OSTROM, E.; WALKER, J. (Ed.). Trust and Reciprocity: Interdisciplinary Lessons for Experimental Research. New York: Russell Sage Foundation. 2005. 
CADERNOS DE COMUNICAÇÃO

UNIVERSIDADE FEDERAL DE SANTA MARIA

Bloomington, 2008. Annals ... Bloomington: Indiana University, 2008.

OSTROM, E; GARDNER, R; WALKER, J. Rules, Games, and Common- Pool Resources. Ann Arbor: The University of Michigan Press, 1994. Disponível em http://www.press.umich.edu/titleDetailDesc.do?id=9739. Acesso em: 19 jul. 2011.

PERUZZO, M. C. Direito à Comunicação Comunitária, Participação Popular e Cidadania. Revista Latinoamericana de Ciencias de la Comunicacion, São Paulo: vol.2, n.3, jul/dic, p. 18-41.2005.

RUDNICKI, C. P. S. As relações de confiança no sistema integrado de producão do tabaco (SIPT) no Rio Grande do Sul/Brasil. Tese (Ḑoutorado em Desenvolvimento Rural), Faculdade de Ciências Econômicas, Universidade Federal do Rio Grande do Sul. 2012.

TEDESCO, J. C. Terra, trabalho e família: racionalidade produtiva e ethos camponês. Passo Fundo: Editora da UPF, 1999.

WANDERLEY, M. N. Raízes históricas do campesinato brasileiro. In: TEDESCO, J. C. (Org.) Agricultura familiar: realidade e perspectivas. Passo Fundo: Editora da UPF, 2001. p. 21-55.

WILLIAMSON, O. E. Strategizing, Economizing, and Economic Organization. Strategic Management Journal, Chicago, v. 12, p. 75-94, Jun. 1991. Special Issue: Fundamental Research Issues in Strategy and Economics.

ZANCHI, V. Roteiros de Turismo Rural nas regiões do Vale do Rio Pardo e Taquari/RS. Dissertação (Mestrado em Desenvolvimento Regional), Pós-Graduação em Desenvolvimento Regional, Úniversidade de Santa Cruz do Sul. 2013. 


\section{Resumo sobre autores:}

\section{Carlise Schneider Rudnicki}

Relações Públicas, Mestre em Doutora em Desenvolvimento Rural/Ciências Econômicas UFRGS/PGDR. Professora Colaboradora PPGCOM/UFRGS e Pós-doutoranda CAPES/ FAPERG, PPGCOM/UFRGS.

E-mail: carlise.schneider@ufrgs.br

\section{Verenice Zanchi}

Doutoranda e mestra em Desenvolvimento Regional pelo PPGDR/UNISC; Especialista em Gestão Empresarial pela FGV; Administradora pelo Centro Universitário UNIVATES; Bolsista CAPES I, Pesquisadora-membro do OBSERVA-DR. Santa Cruz do Sul, RS.

E-mail: verenice.zanchi@gmail.com.br

RECEBIDO EM: 29/06/2016

ACEITO EM: 23/08/2016 